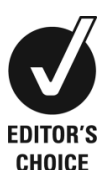

CHOICE

\title{
Familial florid osseous dysplasia: a report with review of the literature
}

\author{
Sercan Kucukkurt, ${ }^{1}$ Sharif Rzayev ${ }_{1}{ }^{2}$ Emre Baris, ${ }^{2}$ Mustafa Sancar Atac ${ }^{2}$
}

${ }^{1}$ Department of Oral and Maxillofacial Surgery, Istanbul Aydin University, Istanbul, Turkey

${ }^{2}$ Department of Oral and Maxillofacial Surgery, Gazi University, Ankara, Turkey

\section{Correspondence to} Dr Sercan Kucukkurt, skucukkurt@gmail.com

Accepted 15 March 2016

\section{(a) CrossMark}

To cite: Kucukkurt $S$, Rzayev S, Baris E, et al. BMJ Case Rep Published online: [please include Day Month Year] doi:10.1136/bcr-2015214162

\section{SUMMARY}

There are three types of osseous dysplasia: periapical cemental dysplasia (PCD), focal cemento-osseous dysplasia (FCD) and florid osseous dysplasia (FOD). While PCD is often observed in mandibular anterior teeth, FCD mainly affects mandibular posterior teeth. FOD, on the other hand, commonly involves both jaws. FOD is a type of sclerosing disease that is characterised by intense opaque masses and many areas with different densities. Genetic heritance of FOD is unusual, with only a few reported cases. We describe a case of FOD that affected three family members, discuss its clinical, radiological and histological characteristics, and review the literature.

\section{BACKGROUND}

Florid cemento-osseous dysplasia (FCOD) is a sclerosing disease characterised by intense opaque masses with many irregular lobules and is generally observed in the jaws and the alveolar process. ${ }^{1}$ FCOD was first identified by Melrose et $a l^{2}$ in 1976 as a subtype of cemento-osseous dysplasia. The current WHO classification (2005) recommends use of the term 'florid osseous dysplasia' (FOD) for this condition, which was previously known as sclerosing osteitis, multiple enostoses, gigantiform cementoma or FCOD. ${ }^{3}$

The disease is mainly observed in middle-aged black females. The ratio of males to females is 1:2.6. ${ }^{4}$ The aetiology of this disease and the reasons for the differences in prevalence between races and genders have not been completely explained. ${ }^{5}$ In many reports, the disease is said to originate from the periodontal ligament, based on its histopathological similarity and occurrence in nearby regions. ${ }^{4}$ However, some studies have argued that it may arise from the cementum remaining in the socket after an extraction. ${ }^{67}$

We describe a case of FOD that affected three family members, discuss its clinical, radiological and histological characteristics, and review the literature.

\section{CASE PRESENTATION}

\section{Case 1 (the mother)}

A 45-year-old female patient was admitted to our oral and maxillofacial surgery department with regional pain around the socket of a tooth which had been extracted a month previously in another clinic. The patient had no systemic disease and her extra-oral appearance was normal. On intra-oral examination, edentulous regions in both jaws were seen together with a necrotic area of bone in the extraction socket. The patient stated that she had had teeth deficiency since birth. She did not complain of paresthesia. Orthopantomography revealed multiple impacted teeth, odontoma-like formations and common lobular, irregular radiopacities ('cotton wool' appearance) affecting the jaws (figure 1). Detailed evaluation of the patient using cone beam CT (CBCT) showed there was no root resorption or correlation between teeth and the lesion. After radiographic evaluation, the decision was made to perform curettage on the extraction socket under antibiotic pressure and simultaneously take a bone biopsy for histopathological diagnosis. The healing period was uneventful. Histopathology revealed large and small bone trabeculae with wide areas on the fibrocellular connective tissue and fibro-osseous lesions compatible with FOD. Osteoblastic rimming and a few osteoclasts were observed around the woven bone trabeculae
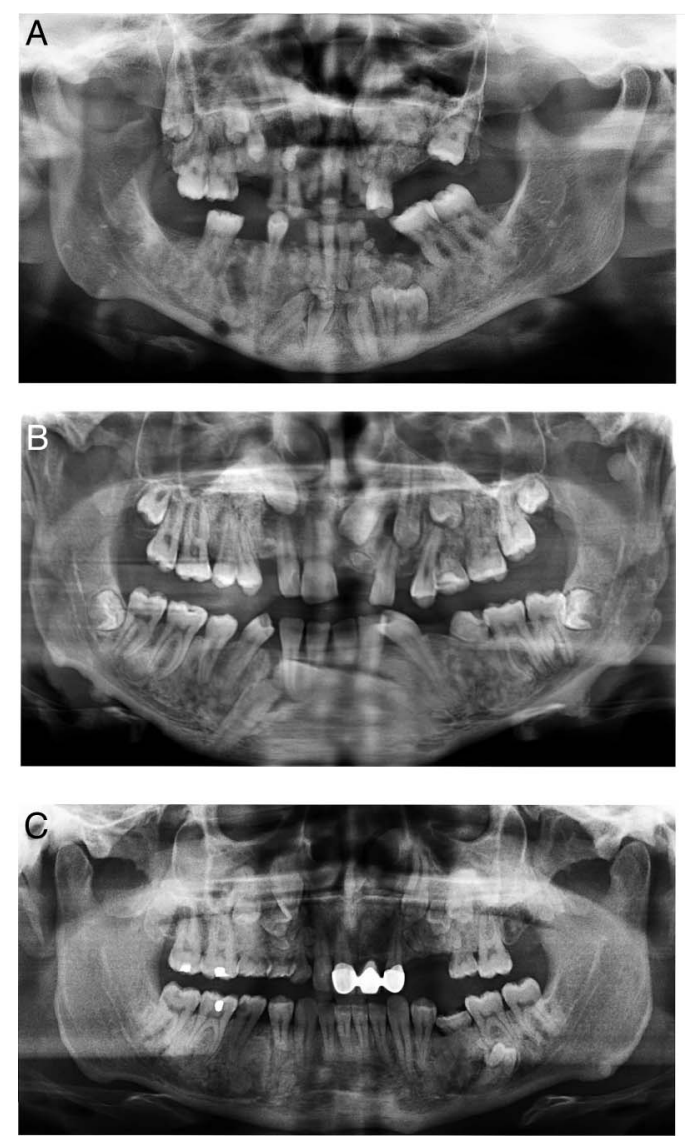

Figure 1 Orthopantomograms of the patients: $(A)$ mother; (B) son; (C) mother's brother. 

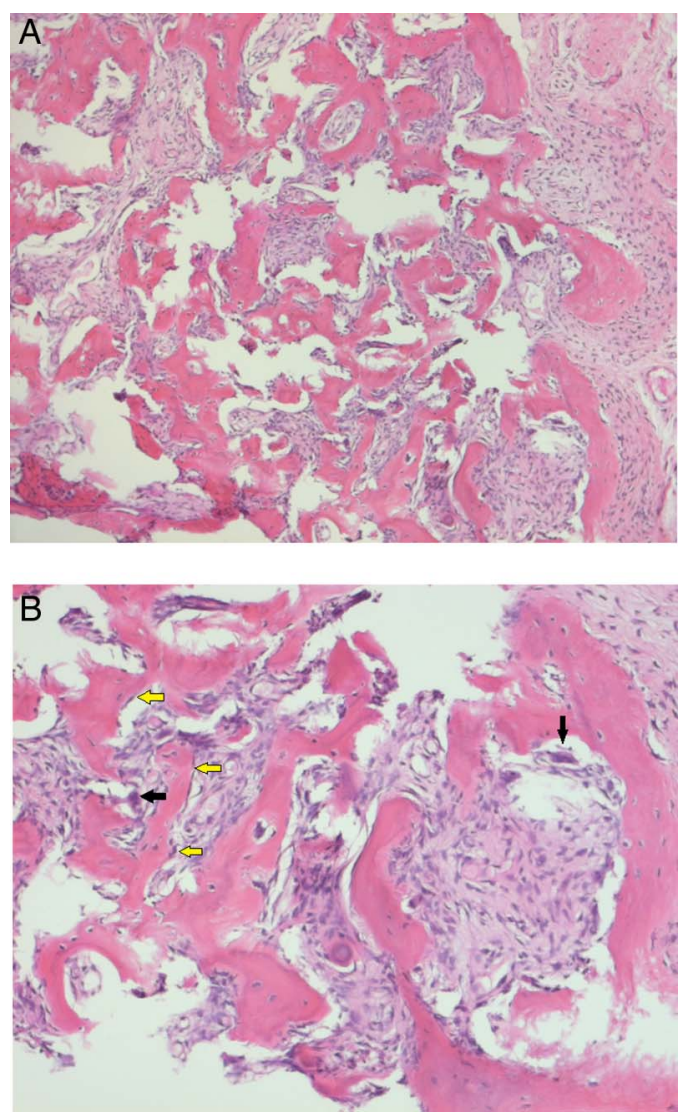

Figure 2 Histologically woven bone trabeculae partly surrounded by osteoblasts(yellow arrows) were seen within fibrocellular connective tissue. A few osteoclasts(black arrows) were also located around the bone trabeculae. (H\&E; A: $\times 100 ; B: \times 200)$.

(figure 2). The patient experienced no problems during the 6-month follow-up period.

\section{Case 2 (the son)}

A 18-year-old male patient was admitted to our department for orthodontic treatment due to malocclusion and missing teeth. The patient did not have systemic disease and intra-oral evaluation revealed all his canines, upper left central incisor, second premolar and lower left second premolar were missing, but the primary molars in the upper and lower left jaws were present. Radiographic examination revealed common lobular, irregularly formed thin radiopacities surrounded by a radiolucent border in all jaw regions (figure 1). The patient was unaware of and did not complain about the jaw lesions.

\section{Case 3 (the mother's brother)}

After the diagnosis of FOD in our first patient and her child, other members of the family were examined and screened for FOD. The anamnesis and examinations showed congenital missing teeth in the brother of our first patient. Clinical and radiographic examination revealed that both of the upper canines and premolars and the lower left second premolar were impacted, and persistent primary teeth were present. Additionally, the patient stated that his upper left central and second molar teeth had never erupted. The radiographic appearance of the entire jaw was the same as in the other patients (figure 1). The patient had no knowledge of the lesions, and had experienced no symptoms.
FOD was not detected in any other examined family member and data showed no other family member had unerupted teeth.

\section{DIFFERENTIAL DIAGNOSIS}

The differential diagnosis is important as many lesions have radiographic features similar to those of FOD. Paget"s disease, chronic diffuse sclerosing osteomyelitis (CDSO), periapical cemental dysplasia (PCD) and familial gigantiform cementoma (FGC) all have similarities with FOD on radiography.

CBCT is a valuable diagnostic tool as it can show the axial, sagittal and frontal sections. It can be used to differentiate FOD from lesions that exhibit a similar sclerotic appearance on conventional radiographs. ${ }^{8}$ In enostosis and exostosis, in which bone intensity increases, axial CBCT can distinguish between the lesion and the cortical layer, unlike occlusal radiography.

While CDSO is detected as a single irregular opaque mass on the jaw, FOD appears as many round or lobular opaque masses. CDSO can affect the entire region from the lower bound of the body of the mandible to the alveolar crest, and even the ramus. ${ }^{9}$ The absence of inflammation eliminates CDSO.

In radiographs, Paget's disease may show a 'cotton wool' type radiopaque appearance in association with hypercementosis. However, this polyostotic disease is generally observed in other bones in addition to the jaw bones. Biochemical analyses showing increased serum alkaline phosphatase, calcium and phosphor can differentiate Paget's disease from FOD. ${ }^{10}$ In our cases, biochemical analyses were only carried out for the mother and showed normal results.

FGC is an autosomal dominant disease mostly observed in young white individuals and causes explicit widening of the jaw. In bone dysplasia other than FGC, widening of the jaw is uncommon and FOD is very rarely observed. ${ }^{5}$ The clinical characteristics of our cases agreed with literature data describing FOD. No widening of the jaw bones was detected in our cases.

Thakkar et $a l^{11}$ and Waldron ${ }^{12}$ reported that the clinical, radiographic and histological differences between PCD, FOD and FGC can be attributed to changes in a single gene or to different clinical findings gathered from lesions belonging to the benign cement osseous dysplasia group.

\section{TREATMENT}

Treatment of FOD depends on current symptoms. Asymptomatic cases generally do not require treatment, but periodic clinical and radiological evaluation is recommended. ${ }^{5}$ If radiological and clinical findings are sufficient for diagnosis, biopsy is not advised so as to avoid infection, sequestrum formation and osteomyelitis; infection is usually associated with impaired vascularisation of the region. However, in symptomatic patients, treatment involves antibiotic therapy and sequestrectomy. ${ }^{13}$ No symptoms were found in our second and third cases, so periodic follow-ups were suggested to prevent possible infection, and information was given on oral hygiene. In our first case, a biopsy was performed as the tooth socket was close to the lesions. Waldron ${ }^{12}$ reported recovery of a bad socket and even sequestrum formation in FOD patients who had had a tooth extracted close to cemental masses. However, in our first case, the necrotic bone was removed from the extraction socket after an incisional biopsy, and recovery was uneventful after primary closure.

\section{DISCUSSION}

Genetic inheritance of FOD and manifestation in members of the same family is unusual, with a limited number of reported 
Table 1 Review of the literature on familial florid osseous dysplasia (FOD)

\begin{tabular}{|c|c|c|c|c|}
\hline & Year & Ethnicity & Involved family members & Reported as \\
\hline Agazzi and Belloni ${ }^{20}$ & 1953 & Italian family & Unspecified & Hard odontomas of the jaws \\
\hline Cannon et $a l^{19}$ & 1980 & Unspecified & Mother and son & Familial gigantiform cementoma \\
\hline Sedano et $a l^{17}$ & 1982 & White family & 10 members & Autosomal dominant cemental dysplasia \\
\hline Young et al ${ }^{16}$ & 1989 & White family & 55 members & Familial gigantiform cementoma \\
\hline Musella and Slater ${ }^{21}$ & 1989 & Italian family & Mother and daughter & Familial florid osseous dysplasia \\
\hline Oikarinen et a/ ${ }^{18}$ & 1991 & Caucasian family & Father and 2 children & Familial gigantiform cementoma \\
\hline Thakkar et al ${ }^{11}$ & 1993 & Caribbean family & Mother, 2 daughters and 1 son & Familial periapical cemental dysplasia \\
\hline Coleman et $a l^{15}$ & 1996 & African family & Mother and 2 children & Familial florid osseous dysplasia \\
\hline Toffanin et $a l^{14}$ & 2000 & Italian family & Grandmother, son, daughter, grandson, granddaughter & Familial florid osseous dysplasia \\
\hline Hatori et $a l^{22}$ & 2003 & Japanese family & Father and daughter & Familial florid osseous dysplasia \\
\hline Srivastava et al ${ }^{9}$ & 2012 & Indian family & Mother and son & Familial florid osseous dysplasia \\
\hline Sim et $a l^{23}$ & 2014 & Asian family & Mother and her identical twin daughters & Familial florid osseous dysplasia \\
\hline Thorawat et $a l^{24}$ & 2015 & Black family & Mother and daughter & Familial florid osseous dysplasia \\
\hline
\end{tabular}

cases. Reviews of the literature indicate that few FOD cases show genetic inheritance (table 1). ${ }^{9}$ 14-19

FOD generally progresses with no symptoms, although in severe cases, pain and regional swelling due to an infection can cause asymmetry of the face. ${ }^{5}$ The disease only involves the jaws and does not affect blood values. ${ }^{12}$

FOD has three stages which produce different radiological images. In the first, osteolytic stage, uniformly bounded radiolucent fields with lamina dura and periodontal ligament loss are observed. In the second, cementoblastic stage, with sedimentation of the cementum-like droplets in fibrous tissue, radiopaque areas begin to form in the radiolucent fields. In the third and final stage, distinct radiopacity is observed in many lesions. ${ }^{13}$

Radiographically, the lesions are observed as multiple sclerotic masses on parts of the jaws with intense teeth in two or more quadrants. Lesions are often seen in all four quadrants. Generally, the lesions are intense on the alveolar crest. Histologically, FOD appears as cement-like calcifications and anastomosing bone trabeculae within the cellular fibroblastic connective tissue. $^{14}$

\section{Learning points}

- Florid osseous dysplasia (FOD) is a type of sclerosing disease that is characterised by intense opaque masses with many irregular lobules.

- Genetic inheritance of FOD and manifestation in members of the same family is rare, with only a limited number of reported cases.

- FOD is treated according to current symptoms; asymptomatic cases generally do not require treatment, but routine clinical and radiological follow-up is advised.

Contributors SK, SR and MSA: treatment of patients; SK and SR: follow-up of patients; SK, SR and MSA: preparation of the manuscript: EB: pathological evaluation of the manuscript; MSA: critical revision of the manuscript.

Competing interests None declared.

Patient consent Obtained.

Provenance and peer review Not commissioned; externally peer reviewed.

\section{REFERENCES}

1 Said-al-Naief NA, Surwillo E. Florid osseous dysplasia of the mandible: report of a case. Compend Contin Educ Dent 1999;20:1017-19, 22-8 passim; quiz 32.

2 Melrose RJ, Abrams AM, Mills BG. Florid osseous dysplasia. A clinical-pathologic study of thirty-four cases. Oral Surg Oral Med Oral Pathol 1976;41:62-82.

3 Mufeed A, Mangalath U, George A, et al. Infected florid osseous dysplasia: clinical and imaging follow-up. BMJ Case Rep 2015;2015; pii: bcr2014209099.

4 Sanjai K, Kumarswamy J, Kumar VK, et al. Florid cemento osseous dysplasia in association with dentigerous cyst. J Oral Maxillofac Pathol 2010;14:63-8.

5 Sarmento DJ, Monteiro BV, de Medeiros AM, et al. Severe florid cemento-osseous dysplasia: a case report treated conservatively and literature review. Oral Maxillofac Surg 2013;17:43-6.

6 Peter A, Philipsen H. Florid cemento-osseous dysplasia. In: Peter A, Philipsen H, eds. Odontogenic tumors and allied lesions. London: Quintessence, 2004:301-9.

7 Paul M, Roman C. Maxillofacial fibro osseous lesions. Curr Diagn Pathol 2006;12:1-10.

8 Damm DD, Fantasia JE. Multifocal mixed radiolucencies. Florid cemento-osseous dysplasia. General Dent 2001;49:461, 538.

9 Srivastava A, Agarwal R, Soni R, et al. Familial florid cemento-osseous dysplasia: a rare manifestation in an Indian family. Case Rep Dent 2012;2012:574125.

10 Dagistan S, Tozoglu U, Goregen M, et al. Florid cemento-osseous dysplasia: a case report. Med Oral Patol Oral Cir Bucal 2007;12:E348-50.

11 Thakkar NS, Horner K, Sloan P. Familial occurrence of periapical cemental dysplasia. Virchows Arch A Pathol Anat Histopathol 1993;423:233-6.

12 Waldron CA. Fibro-osseous lesions of the jaws. J Oral Maxillofac Surg 1993;51:828-35.

13 Kose TE, Kose OD, Karabas HC, et al. Findings of florid cemento-osseous dysplasia: a report of three cases. J Oral Maxillofac Res 2013;4:e4.

14 Toffanin A, Benetti R, Manconi R. Familial florid cemento-osseous dysplasia: a case report. J Oral Maxillofac Surg 2000;58:1440-6.

15 Coleman $\mathrm{H}$, Altini M, Kieser J, et al. Familial florid cemento-osseous dysplasia--a case report and review of the literature. J Dent Assoc S Afr 1996;51:766-70.

16 Young SK, Markowitz NR, Sullivan S, et al. Familial gigantiform cementoma: classification and presentation of a large pedigree. Oral Surg Oral Med Oral Pathol 1989;68:740-7

17 Sedano HO, Kuba R, Gorlin RJ. Autosomal dominant cemental dysplasia. Oral Surg Oral Med Oral Pathol 1982;54:642-6.

18 Oikarinen K, Altonen M, Happonen RP. Gigantiform cementoma affecting a Caucasian family. Br J Oral Maxillofac Surg 1991;29:194-7.

19 Cannon JS, Keller EE, Dahlin DC. Gigantiform cementoma: report of two cases (mother and son). J Oral Surg 1980;38:65-70.

20 Agazzi C, Belloni L. [Hard odontomas of the jaws. Clinico-roentgenologic and anatomo-microscopic contribution with special reference to widely extensive forms with familial occurrence]. Arch Ital Otol Rinol Laringol 1953;64(Suppl. 16):1-103.

21 Musella AE, Slater LJ. Familial florid osseous dysplasia: a case report. J Oral Maxillofac Surg 1989;47:636-40.

22 Hatori M, Ito I, Tachikawa T, et al. Familial florid cemento-osseous dysplasia. Asian J Oral Maxillofac Surg Med Pathol 2003;15:135-7.

$23 \operatorname{Sim}$ YC, Bakhshalian N, Lee J-H, et al. Familial florid cemento-osseous dysplasia in mother and her identical twins: a report with review of the literatures. Oral Surgery 2014; 7:239-44.

24 Thorawat A, Kalkur C, Naikmasur VG, et al. Familial florid cemento-osseous dysplasia_case report and review of literature. Clin Case Rep 2015. 
Copyright 2016 BMJ Publishing Group. All rights reserved. For permission to reuse any of this content visit http://group.bmj.com/group/rights-licensing/permissions.

BMJ Case Report Fellows may re-use this article for personal use and teaching without any further permission.

Become a Fellow of BMJ Case Reports today and you can:

- Submit as many cases as you like

- Enjoy fast sympathetic peer review and rapid publication of accepted articles

- Access all the published articles

- Re-use any of the published material for personal use and teaching without further permission

For information on Institutional Fellowships contact consortiasales@bmjgroup.com

Visit casereports.bmj.com for more articles like this and to become a Fellow 